\title{
Pericyclic versus endodermal lateral roots: which came first?
}

\author{
Authors: Steffen Vanneste ${ }^{1,2,3}$, Tom Beeckman ${ }^{1,2 *}$ \\ ${ }^{1}$ Department of Plant Biotechnology and Bioinformatics, Ghent University, 9052 Ghent, Belgium \\ ${ }^{2}$ Center for Plant Systems Biology, VIB, 9052 Ghent, Belgium \\ ${ }^{3}$ Lab of Plant Growth Analysis, Ghent University Global Campus, Incheon 21985, Republic of Korea. \\ *corresponding author: Beeckman, T. (tobee@psb.vib-ugent.be) \\ https://www.psb.ugent.be/root-development
}

\section{Keywords}

lateral root, evolution, pericycle, endodermis.

\begin{abstract}
Digging into the limited literature on lateral root formation in early vascular plants, we came to the novel conclusion that the pericycle, rather than the endodermis as commonly assumed, represents the ancestral tissue that was evolutionarily recruited to form lateral roots.
\end{abstract}


Roots represent crucial evolutionary inventions for plants that have been indispensable in their conquest of land conditions. They provide the means to explore large volumes of soil for water and nutrients, to establish symbiosis with soil microbes, and provide a solid anchoring point allowing for vertical growth. Fossil records show that the original rooting systems consisted of subterranean, horizontal axes, presumably bearing rhizoids, filamentous tip-growing protrusions of the epidermis. Real roots, demonstrating gravitropic growth and protected by a root cap at their tips, were invented at least twice independently in plant evolution, once in the lycophytes and once in the common ancestor of ferns and seed plants [1,2]. This implies that strategies to branch were also invented independently. Indeed, lycophytes branch terminally involving meristem dichotomy, while (ferns and fern allies) and seed plants (gymnosperms and angiosperms) display lateral root branching. An important distinctive character between extant ferns and seed plants is that LRs in ferns mainly derive from the endodermis, while in seed plants LRs originate from the pericycle, often with contributions of the endodermis. This raises the question: Which of these tissues contained the ancestral competence to form lateral roots?

\section{Lateral root formation in seed plants}

The pericycle, the specialized outer ring of the stele, has been recognized for more than 150 years for its role in LR formation in seed plants $[3,4]$. This is in most species a single contiguous cell layer, from which subsets of cells are selected by the integration of endogenous and exogenous signals to undergo lateral root initiation. This can easily be demonstrated in Arabidopsis thaliana by applying auxin which potently activates lateral root initiation along the entire root [5]. It is, however, important to note that not all pericycle cells have an equal LR stem cell competence. Instead, pericyclic LR stem cell competence is strictly associated with the position relative to xylem or phloem poles of the vascular cylinder. In most seed plants only the pericycle cells located at the xylem poles can undergo lateral root initiation $[3,4,6]$. Some initiate LRs in front of phloem poles or in between phloem and xylem poles, either due to interruption of the pericycle (eg. grasses) or to the formation of oil or resin channels (eg. Umbelliferae and Araliaceae) at the xylem poles [4].

It is, however, important to note that the pericycle is not the only tissue that participates in the formation of a lateral root. A recent anatomical survey over a wide variety of species has shown that cells from the endodermis and even the cortex can participate in lateral root formation as well, not only by accommodating passage of the growing meristem, but also by a real contribution of stem cells to the lateral root from early developmental stages onwards [7], suggesting primordium initiation is not restricted to a single tissue. In fact, this is in line with older studies, defining multiple types of LR development, based on the relative contributions of pericycle, endodermis and even cortical cells to the LR primordium [6,8]. Notably, in each of these cases the pericycle gives rise to the vascular tissue of the $L R$, and are therefore defined as pericyclic LRs. Again, pteridophytes were underrepresented in these systematic analyses.

Despite this variety of types, the main body of the primordium for each of the analyzed seed plant species, derives from the pericycle, suggesting that the propensity to form lateral roots from the pericycle, whether or not with contributions of the endodermis, was probably present in the last common ancestor of seed plants (LCA-S) (Figure 1). 


\section{Lateral root formation in pteridophytes}

Pteridophytes are of great evolutionary significance for root development in seed plants as they evolved from a shared root bearing ancestor. Yet, there is a harrowing lack in the knowledge of their root biology and root branching patterns. Furthermore, the few studies on fern roots are skewed towards the group of leptosporangiate ferns, that represent the largest fraction (>80\%) of extant pteridophytes. This bias is already apparent in seminal work on early LR development in ferns by Nägeli and Leitgeb [3]. In each of the 6 leptosporangiate ferns investigated, representing Thelypteridaceae, Pteridaceae and Marsileaceae, they found lateral roots originating from the endodermis, and are here defined as endodermis-derived LRs. Later, the endodermal origin of LRs was interpreted as the endodermis being the outer layer of the stele instead of the pericycle [8]. When focusing on the early divergence of pteridophytes, one could be tempted to speculate that endodermis-derived lateral root formation is evolutionary older than pericyclederived LR formation, as seen in seed plants, and thus ancestral. However, it is important to realize that the bulk of leptosporangiate ferns diversified relatively recently [9], and that endodermis-derived LR formation could represent a recent evolutionary innovation within this clade (Figure 1).

Within the phylogenetic tree of pteridophytes, the Equisetaceae and Marratiaceae represent early diverging lineages, with Equisetaceae diverging from leptosporangiates about $350 \mathrm{Mya}$, and from seed plants about 380 Mya [9]. Intriguingly, Equisetum scirpoides (Equisetaceae), develops lateral roots from pericycle cells adjacent to the xylem axis [10]. Reminiscent of many seed plants, the endodermis of Equisetum fluviatile also participates in the lateral root formation [7]. Notably, in an attempt to keep the central idea of endodermal-derived lateral root initiation in ferns, it has been argued that Equisetaceae lack a pericycle, and instead have a double endodermis [3]. Similarly, early diverging Angiopteris lygodifolia (Marattiaceae), and Botrichium lunaria (Ophioglossaceae) also develop lateral roots from their pericycle, albeit positioned between the phloem and xylem axis [11]. Making abstraction of the nonunambiguity of the Marattiaceae observation [4], these examples illustrate that early diverged fern lineages form lateral roots from their pericycle, suggesting that the shift in LR initiation competence to the endodermis in leptosporangiates was a recent evolutionary innovation. Consistently, Osmundaceae, slowly evolving leptosporangiates [12], are intermediate in many ways between eusporangiates and leptosporangiates, and develop LRs from their pericycle as well [11]. Given the relative morphological stasis of Osmundaceae and Equisetaceae over time, we conclude that the pericycle is probably the ancestral tissue from which LR originated in pteridophytes. We therefore postulate that in the last common, root bearing, ancestor of pteridophytes and seed plants, the pericycle, with early participation of the endodermis [7], biased evolution towards LR formation from these tissues in seed plants (Fig. 1; LCA). In this scenario, modern leptosporangiates transferred the LR founder cell function from pericycle to endodermis completely, while in seed plants the pericycle was kept as LR founder tissue with, in some cases, the endodermis evolving to a more coordinative signaling function, as seen in Arabidopsis thaliana [13].

\section{Outlook}

Demonstrating the proposed ancestral pericyclic origin of $L R$ formation will require a detailed understanding of the molecular determinants of LR stem cell competence and how these evolved. Very recently, it was proposed that LR branching evolved at least independently in the seed plants, Equisetopsida and leptosporangiates [14]. The common denominator for all clades is the recruitment of cells (pericycle, endodermis or both) in the proximity of vascular tissues which would argue for a positional 
ancestral competence rather than the proposed tissue-based ancestral competence. The arrival of the era of single cell RNA sequencing thus heralds the promise of answering this question as it allows outlining the developmental trajectories and molecular determinants of pericycle and endodermis identity for species at key evolutionary positions and help resolving this pertinent question.

\section{Acknowledgements}

We thank Maria Njo for help with the preparation of the artwork.

\section{References}

1. Hetherington, A.J. and Dolan, L. (2018) Stepwise and independent origins of roots among land plants. Nature 561, 235-238.

2. Kenrick, P. and Strullu-Derrien, C. (2014) The origin and early evolution of roots. Plant Phys. 166, 570-580.

3. Nägeli, C. and Leitgeb, H. (1868) Entstehung and Wachsthum der Wurzeln. In Beitrage zur wissenschaftlichen Botanik (Heft 4) (Nägeli, C., Leitgeb, H. and Schwendener, S. eds.), pp 73-159, Leipzig: W. Engelmann.

4. van Tieghem, P. (1870) Recherches sûr la symétrie de structure dans les plantes vasculaires. Ann. Sci. Nat. Série5, t13: 5-314.

5. Himanen, K. et al. (2002) Auxin-mediated cell cycle activation during early lateral root initiation. Plant Cell 14, 2339-2351.

6. de Janczewski, E. (1874) Recherces sur le développement des radicelles dans les phanérogames. Ann. Sci. Nat. Série5, t20: 208-233.

7. Xiao, T.T. et al. (2019) Lateral root formation involving cell division in both pericycle, cortex and endodermis is a common and ancestral trait in seed plants. Development 146: dev182592.

8. van Tieghem, P. and Douliot H. (1887) Origine de radicelles et des racines latérales dans les Rubiacées, les Violacées et les Apocynées. Bull. Soc. Bot. France 34, 150-154.

9. Schneider, H. et al. (2004) Ferns diversified in the shadow of angiosperms. Nature 428, 553-557.

10. Johnson, M.A. (1933) Origin and development of tissues in Equisetum scirpoides. Bot. Gaz. 94: 469-494.

11. Chiang, S.T. and Chou, T. (1974) Tissue differentiation in the roots of some ferns. Taiwania, 19: 718.

12. Schneider, H. et al. (2015) Are the genomes of royal ferns really frozen in time? Evidence for coinciding genome stability and limited evolvability in the royal ferns. New Phytol. 207: 10-13.

13. Vermeer, J.E.M. et al. (2014) A spatial accommodation by neighboring cells is required for organ initiation in Arabidopsis. Science 343, 178-183.

14. Hetherington, A.J. et al. (2020) Multiple origins of dichotomous and lateral branching during root evolution. Nat. plants https://doi.org/10.1038/s41477-020-0646-y 


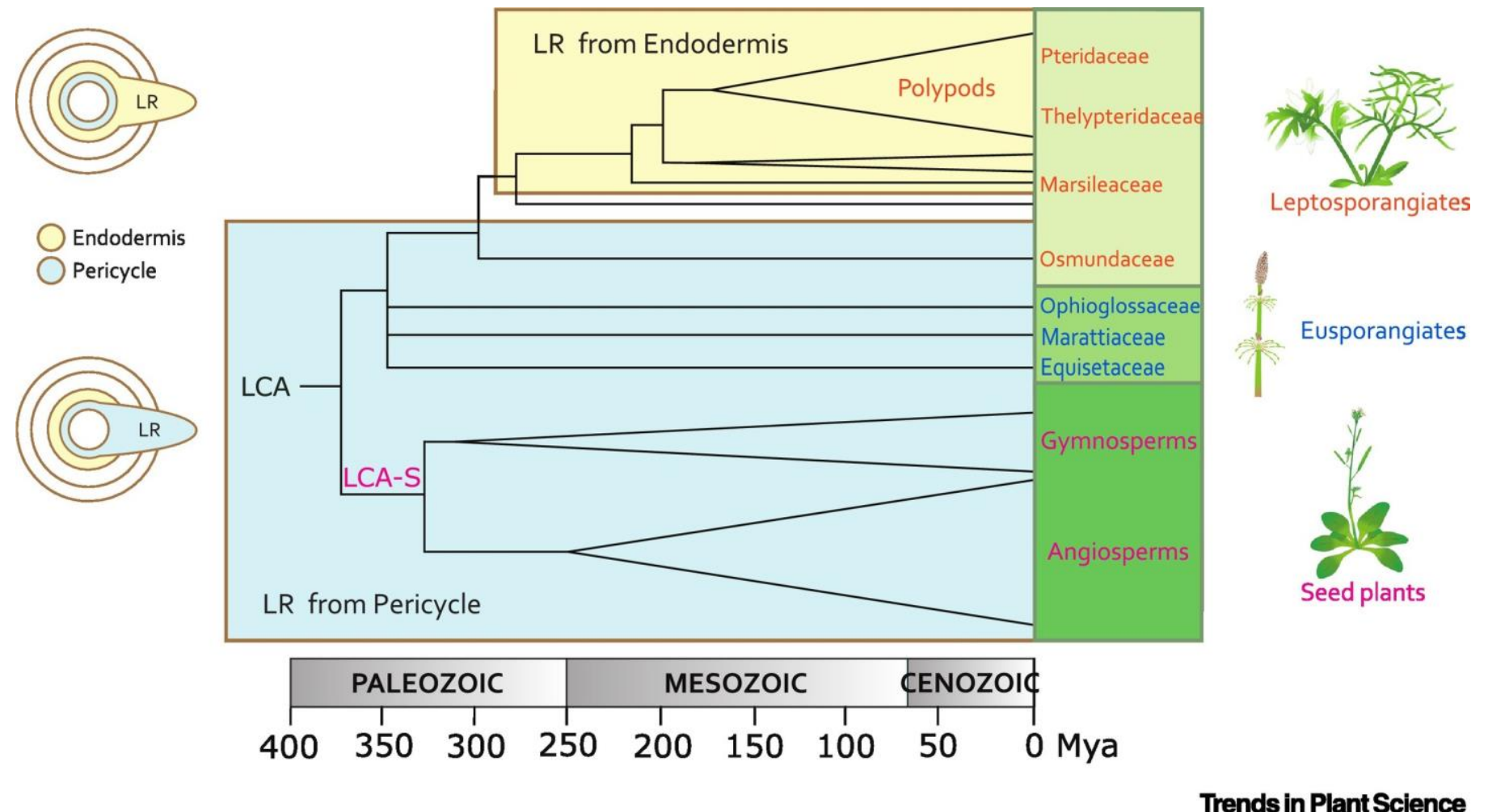

Figure 1: Evolution of LR formation across pteridophytes and seed plants. Left, schematic representation of the two main types of LR formation (endodermis (yellow) versus pericycle (blue) derived LRs). The phylogenetic tree shows the key subdivisions among the pteridophytes and seed plants, matching timings as estimated by [8]. The indicated families and lineages are mentioned in the text. LCA is the last common ancestor of the pteridophytes and seed plants. LCA-S is the last common ancestor of the seed plants. 